\title{
POLYELECTROLYTE MODIFIED SILICA GEL MICRO-COLUMN SOLID PHASE EXTRACTION FOR THE DETERMINATION OF SILVER IN ENVIRONMENTAL WATER SAMPLES BY FLAME ATOMIC ABSORPTION SPECTROMETRY
}

\author{
GUOQIANG XIANG*, LULU LI, XIUMING JIANG, LIJUN HE, LU FAN \\ School of chemistry and chemical engineering, henan University of technology. Zhengzhou city, 450001, P.R. China
}

(Received: October 17, 2012 - Accepted: May 13, 2013)

\begin{abstract}
Silica gel was chemically modified with polyelectrolyte and used as a solid phase extraction adsorbent for the determination of trace silver in environmental water samples by flame absorption spectrometry (FAAS). The effects of $\mathrm{pH}$, sample flow rate and volume, elution conditions and co-existing ions on the recovery of the analyte were investigated. The results showed that silver could be adsorbed at $\mathrm{pH} 5.0$ and eluted by $5.0 \mathrm{~mL} 2 \%$ thiourea in $\mathrm{HNO}_{3}\left(0.1 \mathrm{~mol} \mathrm{~L}^{-1}\right)$. Under the optimized conditions, the adsorption capacity of modified silica gel was found to be $8.6 \mathrm{mg} \mathrm{g}^{-1}$ for silver. The detection limit of the proposed method was $1.0 \mathrm{ng}$ $\mathrm{mL}^{-1}$ for silver with an enrichment factor of 18.7. The analytical result for the certified reference water sample (GBW08610) was in a good agreement with the certified value. The proposed method has also been successfully applied to the determination of trace silver in drinking water, well water, snow water and waste water with the recoveries for spiked samples between $94 \%$ and $105 \%$.
\end{abstract}

Key words: Polyelectrolyte; Silica gel; Solid phase extraction; Silver; Water samples; FAAS

\section{INTRODUCTION}

Silver is an essential environmental element, and it is toxic for biological systems. Unfortunately, the silver contamination for environment became a serious problem with the widespread use of silver compounds and silvercontaining procedures in different industry and manufacturing fields, such as water disinfection with silver impregnated filters, silver ion antimicrobial for human health, metal ores industry[1-3]. Thus, it is important to develop analytical methods for the monitoring of silver in environment samples.

Compared with other elemental detectors, FAAS has the characteristics of good precision, simple operation and lower cost. However, its insufficient sensitivity and matrix effect make it difficult for the direct determination of metals at trace level in the complicated samples by FAAS[4]. To solve this problem, separation-preconcentration procedure prior to determination by FAAS is a popular choice. Preconcentration is a very important issue for improvement of sensitivity, and separation is an efficient technique to reduce the interference of sample matrix[5]. Various separation-preconcentration procedures have been used for this purpose, including liquid-liquid extraction[6], solid phase extraction[7-9], ion exchange techniques[10], coprecipitation[11] and cloud point extraction[12-13].

Recently, solid phase extraction (SPE) technique has become increasingly popular for the enrichment of metal ions prior to their determination. Compared with traditional liquid-liquid extraction methods, SPE technique has the following characteristic advantages, such as high preconcentration factor, simple operation, rapid phase separation, reduced operation time and cost, and convenient combination with different detection techniques[5,14].

It is well known that the adsorption medium plays a key role in improving the analytical performance of SPE and much more attention has been paid to the investigation of new materials for SPE in recent years[15] Among wide range of solid adsorbents, such as chelating resins, silica gel, carbon sorbents, inorganic based sorbents, biological adsorption material and nanomaterials[5,15-18], silica gel bonded chelating ligands has gained much more importance for metal ion enrichment for its definite advantages, such as good mechanical strength, no swelling and straining, good thermal stability and convenient chemical modification[19].

In this paper, a polyelectrolyte containing thiol ligand was bonded onto the surface of silica gel, and the obtained adsorbent was used for the enrichment of trace silver in environmental water samples. The SPE preconcentration procedure was combined with FAAS for the determination of trace silver in different environmental water samples.

\section{EXPERIMENTAL}

\section{Apparatus}

TAS-986 atomic absorption spectrometry (Beijing purkinje general instrument Co., Ltd., Beijing, China.) with silver hollow cathode lamps (KY-1 type, wavelength $328.1 \mathrm{~nm}$ ) was used for the determination. The instrumental parameters used were those recommended by the manufacture. The $\mathrm{pH}$ values were controlled with a PHS-3C pH-meter (Shanghai precision \& scientific instrument co., Ltd., Shanghai, China). A HL-2D constant flow pump (Shanghai Qingpu Huxi Instrument Factory, Shanghai, China) and a self-made poly-tetrafluoroethylene (PTFE) micro-column $(30 \mathrm{~mm} \times 4.0 \mathrm{~mm}$, i.d.) packed with polyelectrolyte modified silica gel was used in the solid phase extraction process.

Standard solutions and reagents

All reagents used were analytical-reagent grade. Amino bonded silica gel (average diameter 45-75 mm, Fuji Chromatorex) and polyisobutylene-altmaleic anhydride (Mw 6000) were purchased from sigma-aldrich. L-cysteine and N,N-dimethylformamide (DMF) (AR, Shanghai Huixing Biochemical Reagent Company, Shanghai, China) were used for reaction directly. The stock standard solutions $\left(1.000 \mathrm{~g} \mathrm{~L}^{-1}\right)$ of silver was prepared by dissolving appropriate amounts of silver nitrate (Sinopharm Chemical Reagent Co.,

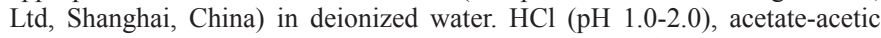
acid buffer ( $\mathrm{pH} 3.0-5.0)$ and $\mathrm{NaOH}$ solution $\left(0.1 \mathrm{~mol} \mathrm{~L}^{-1}\right)$ were used for $\mathrm{pH}$ adjustment. Different stock solutions of potentially interfering ions $(1.000 \mathrm{~g}$ $\mathrm{L}^{-1}$ ) were prepared according to the conventional method. Working solutions were prepared daily by appropriate dilutions of stock solutions in brown flask. The laboratory glassware was kept in a $5 \%(\mathrm{v} / \mathrm{v})$ nitric acid solution overnight. Afterwards, it was rinsed thoroughly with deionized water and dried.

\section{Preparation of the adsorbent}

The preparation of the polyelectrolyte modified silica gel was illustrated in Fig.1. Firstly, polyisobutylene-alt-maleic anhydride (2.5 g) and L-cysteine $(1.5 \mathrm{~g})$ was dissolved in DMF $(250 \mathrm{~mL})$, then refluxed at $130{ }^{\circ} \mathrm{C}$ for $1 \mathrm{~h}$ with magnetic stirring. After refluxing, the reactant was cooled to room temperature, and the amino-bonded silica gel $(1.5 \mathrm{~g})$ was added, and refluxed at $130{ }^{\circ} \mathrm{C}$ for $1.5 \mathrm{~h}$ with magnetic stirring.After cooled to room temperature, the resultant product was collected through decompress filter. The obtained particles was washed with methanol $(100 \mathrm{~mL})$ and deionized water $(100 \mathrm{~mL})$, and dried in vaccum.

\section{Preparation of micro-column}

A total of $70 \mathrm{mg}$ of polyelectrolyte modified silica gel was filled into a PTFE micro-column $(30 \mathrm{~mm} \times 4.0 \mathrm{~mm}$, i.d.) plugged with a small portion of adsorbent cotton at both ends. Before use, deionized water was passed through the column in order to clean it.

Procedure of column experiments

In the column experiments, a $100.0 \mathrm{~mL}$ sample or standard solution containing silver was adjusted to $\mathrm{pH} 5.0$ and was passed through the column by using a peristaltic pump at $3.5 \mathrm{~mL} \mathrm{~min}^{-1}$ of sample flow rate. Afterwards, silver 
retained on the column was eluted with $5.0 \mathrm{~mL} 2 \%$ thiourea in $\mathrm{HNO}_{3}(0.1 \mathrm{~mol}$ $\mathrm{L}^{-1}$ ) at elution flow rate of $1.0 \mathrm{~mL} \mathrm{~min}^{-1}$. Finally, the analyte in the effluents was determined by FAAS.

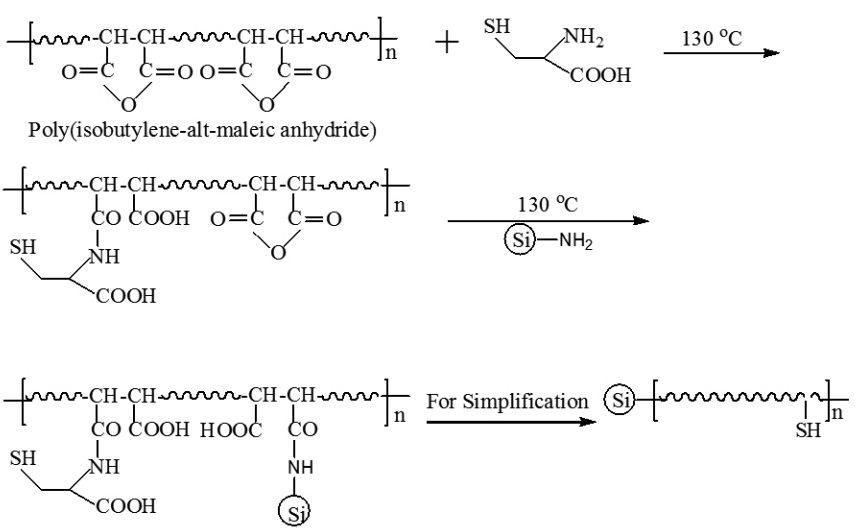

Fig.1: Illustration of synthesis of polyelectrolyte modified silica gel adsorbent.

\section{Sample preparation}

Tap water, well water and snow water were collected in the campus (Henan University of Technology ). The waste water was collected in a printworks in Zhengzhou city, China. And then several drops of $\mathrm{HNO}_{3}\left(0.5 \mathrm{~mol} \mathrm{~L}^{-1}\right)$ were added into the water samples. After filtration, the water was passed through $0.45 \mu \mathrm{m}$ filtration membrane, the obtained water was used for determination.

\section{RESULTS AND DISCUSSION}

Characterization of polyelectrolyte modified silica gel

The elemental analysis results for the polyelectrolyte modified silica gel was as follow: N $13.9 \%$ (wt), C $42.5 \%$ (wt), H 7.7\% (wt), S 5.1\% (wt). And the amount of thiol ligand on the obtained polyelectrolyte modified silica gel was determined according to the Ellman method[20]. It was found that the amount of thiol ligand on the polyelectrolyte modified silica gel was $0.292 \mathrm{mmol} \mathrm{g}^{-1}$. The above details clearly demonstrated the successful modification of silica gel with polyelectrolyte containing thiol ligand.

Effect of $\mathrm{pH}$

$\mathrm{pH}$ value plays a key role in the SPE procedure. An appropriate $\mathrm{pH}$ value can not only improve the adsorption efficiency, but also depress the interference of sample matrix. The adsorption behavior of silver on polyelectrolyte modified silica gel was studied according to the procedure of column experiments. The effect of $\mathrm{pH}$ on the adsorption ( $\mathrm{R} \%$ ) of sivler on polyelectrolyte modified silica gel was showed in Fig.2. It can be seen that silver was adsorbed quantitatively ( $\mathrm{R}$ larger than $90 \%$ ) on polyelectrolyte modified silica gel within a $\mathrm{pH}$ range of 4-7. The precipitate was observed with $\mathrm{pH}$ larger than 7, for further experiments, $\mathrm{pH} 5.0$ was chosen for preconcentration of silver.

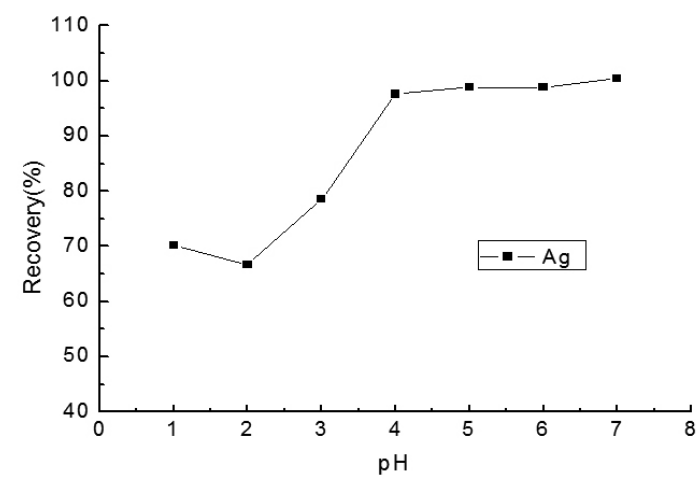

Fig.2: Effect of $\mathrm{pH}$ on the adsorption (R\%) of silver on polyelectrolyte modified silica gel. The concentration of target analytes: $\mathrm{Ag}^{+} 0.5 \mu \mathrm{g} \mathrm{mL} L^{-1}$, sample flow rate: $3.5 \mathrm{~mL} \mathrm{~min}^{-1}$, sample volume: $100 \mathrm{~mL}$, eluent flow rate: 1.0 $\mathrm{mL} \min ^{-1}$
Optimization of elution conditions

It is obvious from Fig.2 that the adsorptions of silver decrease sharply with the decrease of $\mathrm{pH}$ value. For this reason, various concentrations $\left(0.5 \mathrm{~mol} \mathrm{~L}^{-1}\right.$ $\left.2.0 \mathrm{~mol} \mathrm{~L}^{-1}\right)$ of $\mathrm{HNO}_{3}$ were studied for the elution of retained analytes at $0.5 \mathrm{~mL}$ $\mathrm{min}^{-1}$ of elution flow rate. The results showed that quantitative recoveries (> $90 \%$ ) could not be obtained in the tested $\mathrm{HNO}_{3}$ concentration range. This could be explained by the fact that chelate of $\mathrm{Ag}^{+}$and - $\mathrm{SH}$ is very stable and $\mathrm{HNO}_{3}$ could not elute it from the column. To obtain quantitative elution, different elution solutions, such as thiourea, $\mathrm{NH}_{4} \mathrm{SCN}, \mathrm{HNO}_{3}$ and thiourea (mixed), and $\mathrm{HNO}_{3}$ and $\mathrm{NH}_{4} \mathrm{SCN}$ (mixed) were tested. The results indicated that mixed $\mathrm{HNO}_{3}$ and thiourea solution was a good eluent for silver on the column. And it was found that quantitative recoveries $(>90 \%)$ could be obtained by $2 \%$ thiourea in $\mathrm{HNO}_{3}\left(0.1 \mathrm{~mol} \mathrm{~L}^{-1}\right)$ solution.

The elution volume and elution flow rate could affect the elution efficiency remarkably. By using $2 \%$ thiourea in $\mathrm{HNO}_{3}\left(0.1 \mathrm{~mol} \mathrm{~L}^{-1}\right)$ solution as the eluent, the effect of elution volume on the quantitatively elution of analytes was investigated according to the procedure of column experiments. $10.0 \mathrm{~mL}$ of eluent was used to elute the analytes on the polyelectrolyte modified silica gel, the eluent was collected at $1.0 \mathrm{~mL}$ intervals. Fig. 3 showed the recovery of analytes in each portion determined by FAAS. As can be seen, the recovery of analytes was larger than $95 \%$ when eluent volume larger than $4.0 \mathrm{~mL}$. That means quantitatively elution could be obtained when elution volume higher than $4.0 \mathrm{~mL}$ for silver. And it was also found that quantitatively elution could be obtained with elution flow rate no more than $1.0 \mathrm{~mL} \mathrm{~min}^{-1}$. Thus, the elution conditions used in the following experiments were as follow: the eluent $2 \%$ thiourea in $\mathrm{HNO}_{3}\left(0.1 \mathrm{~mol} \mathrm{~L}^{-1}\right)$ solution elution volume was $5.0 \mathrm{~mL}$ and the elution flow rate was $1.0 \mathrm{~mL} \mathrm{~min}^{-1}$.

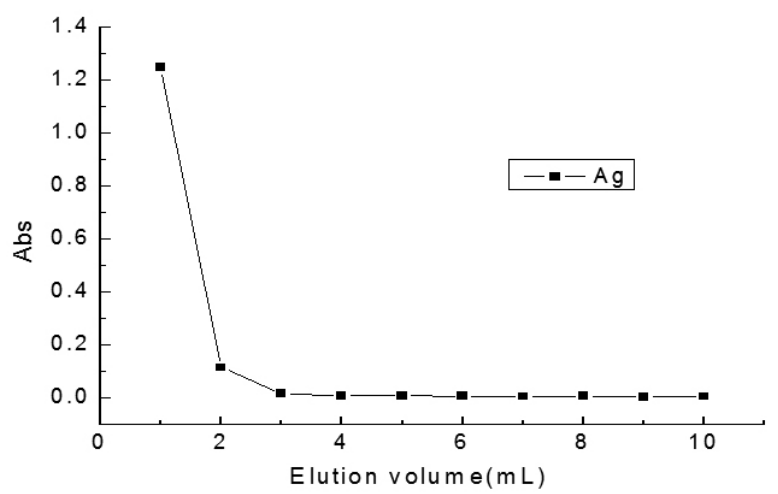

Fig.3: Effect of eluent volume on the recovery of silver. The concentration of target analyte: $\mathrm{Ag}^{+} 0.5 \mu \mathrm{g} \mathrm{mL} \mathrm{m}^{-1}$, sample flow rate: $3.5 \mathrm{~mL} \mathrm{~min}^{-1}$, sample volume: $100 \mathrm{~mL}$, eluent flow rate: $1.0 \mathrm{~mL} \mathrm{~min}^{-1}$

Effect of sample flow rate and sample volume

The sample flow rate should be optimized to ensure quantitatively retention along with minimization of the time required for sample processing. It was found that the flow rate in the range of $0.5-3.5 \mathrm{~mL} \mathrm{~min}^{-1}$ had no significant effect on the recoveries of silver according to the procedure of column experiments. For further experiments, $3.5 \mathrm{~mL} \mathrm{~min}{ }^{-1}$ was chosen as the sample flow rate.

In order to obtain a high or achievable preconcentration factor of very dilute analyte solutions from large volumes, it is imperative to investigate the effect of sample volume on the retention of analytes on the modified silica gel. It was found that quantitative recovery for silver was obtained when sample volumes were less than $100 \mathrm{~mL}$. So an theoretical enrichment factor of 20 can be achieved by this method.

\section{Effect of co-existing ions}

The effect of potential co-existing ions on the preconcentration and determination of the studied analyte was investigated. In this experiment, the silver standard solution $\left(20.0 \mathrm{ng} \mathrm{mL}^{-1}\right)$ containing the added interfering ions were treated according to the procedure of column experiments. The content of silver in the eluent was determined in order to calculate the recovery of analyte. The tolerances of the co-existing ions, defined as the maximum concentration of co-existing ion that could achieve $>90 \%$ recovery of silver were given in Table 1. It could be seen that the presence of major cations had no obvious influence on the target element adsorption under the selected conditions except for $\mathrm{Cu}^{2+}$. The could be explained by the fact the chelation absorption capability 
of thiol ligand for $\mathrm{Cu}^{2+}$ is slightly lower than that for $\mathrm{Ag}^{+}$.

Table 1. Tolerance limits of co-existing ions

\begin{tabular}{|c|c|c|}
\hline Substance & Maximum tolerable amount & Recovery(\%) \\
\hline $\mathrm{Na}^{+}$ & $60 \mu \mathrm{g} \mathrm{mL}^{-1}$ & 103.5 \\
\hline $\mathrm{K}^{+}$ & $100 \mu \mathrm{g} \mathrm{mL}^{-1}$ & 97.9 \\
\hline $\mathrm{Ca}^{2+}$ & $50 \mu \mathrm{g} \mathrm{mL}^{-1}$ & 101.4 \\
\hline $\mathrm{Mg}^{2+}$ & $100 \mu \mathrm{g} \mathrm{mL}^{-1}$ & 105.0 \\
\hline $\mathrm{Zn}^{2+}$ & $1.0 \mu \mathrm{g} \mathrm{mL}^{-1}$ & 94.5 \\
\hline $\mathrm{Pb}^{2+}$ & $6.0 \mu \mathrm{g} \mathrm{mL}^{-1}$ & 101.6 \\
\hline $\mathrm{Cd}^{2+}$ & $1.0 \mu \mathrm{g} \mathrm{mL}^{-1}$ & 100.0 \\
\hline $\mathrm{Ni}^{2+}$ & $4.0 \mu \mathrm{g} \mathrm{mL}^{-1}$ & 92.6 \\
\hline $\mathrm{Cu}^{2+}$ & $0.05 \mu \mathrm{g} \mathrm{mL}^{-1}$ & 94.5 \\
\hline $\mathrm{Co}^{2+}$ & $4.0 \mu \mathrm{g} \mathrm{mL}^{-1}$ & 100.2 \\
\hline
\end{tabular}

Column regenerability and adsorption capacity

The regenerability and stability of the column was investigated by passing the silver standard solution $\left(100 \mathrm{~mL}, 20 \mathrm{ng} \mathrm{mL}^{-1}\right)$ and then passing $5.0 \mathrm{~mL}$ of thiourea $(2 \%, \mathrm{~m} / \mathrm{v})$ in nitric acid $\left(0.1 \mathrm{~mol} \mathrm{~L}^{-1}\right)$ solution and $10 \mathrm{~mL}$ of deionized water through the column packed with $70 \mathrm{mg}$ of polyelectrolyte modified silica gel. It was observed that the column could be reused up to 40 runs with the recoveries of the target ion larger than $90 \%$.

The adsorption capacity of polyelectrolyte modified silica gel was studied in order to evaluate the amount of adsorbent required to quantitatively concentrate the analyte from a given solution. The method used was adapted from the recommended procedure by Maquieira et al.[21].The adsorption capacities of silver was $8.6 \mathrm{mg} \mathrm{g}^{-1}$.

\section{Analytical performance}

Under the optimized experiment conditions, the analytical performance of the method was evaluated. Based on the definition of IUPAC, the detection limits $(3 \sigma)$ of this method was $1.0 \mathrm{ng} \mathrm{mL}^{-1}$ for silver, the relative standard deviation (RSD) were $2.9 \%\left(\mathrm{c}=20 \mathrm{ng} \mathrm{mL} \mathrm{m}^{-1}, \mathrm{n}=7\right)$. The calibration curve for the preconcentration procedure was $\mathrm{A}=0.0029 \mathrm{C}+0.017(\mathrm{R}=0.997)$ for $5-50 \mathrm{ng}$ $\mathrm{mL}^{-1}$, and the calibration curve without preconcentration was $\mathrm{A}=0.000155 \mathrm{C}$ $0.0305(\mathrm{R}=0.997)$. The enrichment factor $(\mathrm{EF}$, calculated as the ratio of the slopes of the calibration curve with preconcentration and direct aspiration, respectively) was 18.7 .

\section{Sample analysis}

For real sample analysis, the standard calibration curve method was employed. In order to evaluate the validity of the procedure, the method has been applied to the determination of silver in the certified reference sample (GBW08610 water sample). The analytical results showed a good agreement between the determined values $\left(0.976 \pm 0.006 \mathrm{mg} \mathrm{mL}^{-1}\right)$ and the certified values $\left(1.000 \pm 0.001 \mathrm{mg} \mathrm{mL}^{-1}\right)$.

The proposed method was also applied to the determination of trace silver in river water (drinking water, well water, snow water and waste water). The analytical results and the recoveries for the spiked samples were given in Table 2 . It could be seen that the recoveries for the spiked samples is between $94 \%$ and $112 \%$.

\section{CONCLUSION}

A simple, rapid and reliable method was developed for the preconcentration and FAAS determination of trace silver in environmental water samples by using polyelectrolyte modified silica gel as micro-column packing material The adsorption behavior of silver on polyelectrolyte modified silica gel had been systematically studied. It was found that polyelectrolyte modified silica gel showed a high adsorption capacity for silver, and the analyte retained on its surface can be easily desorbed. Hence, polyelectrolyte modified silica gel showed great potential as an adsorbent for the preconcentration of trace metal ions in samples with complicated matrix.
Table 2. Analytical results for $\mathrm{Cu}^{2+}$ in river water samples (mean $\pm \mathrm{SD}, \mathrm{n}=3$ )

\begin{tabular}{|c|c|c|c|}
\hline Sample $\left(\mathrm{ng} \mathrm{mL}^{-1}\right)$ & Added & Found & Recovery \\
\hline \multirow{3}{*}{$\begin{array}{c}\text { Drinking water } \\
\left(\mathrm{ng} \mathrm{mL} \mathrm{m}^{-1}\right)\end{array}$} & 0 & - & - \\
\cline { 2 - 4 } & 10 & $9.8 \pm 0.2$ & $98 \%$ \\
\cline { 2 - 4 } & 20 & $21.0 \pm 0.5$ & $105 \%$ \\
\hline \multirow{4}{*}{$\begin{array}{c}\text { Well water } \\
\left(\mathrm{ng} \mathrm{mL} \mathrm{mL}^{-1}\right)\end{array}$} & 0 & - & - \\
\cline { 2 - 4 } & 10 & $9.4 \pm 0.3$ & $94 \%$ \\
\hline \multirow{4}{*}{$\begin{array}{c}\text { Snow water } \\
\left(\mathrm{ng} \mathrm{mL} \mathrm{mL}^{-1}\right)\end{array}$} & 10 & $19.2 \pm 0.6$ & $96 \%$ \\
\cline { 2 - 4 } & 20 & - & - \\
\hline \multirow{3}{*}{$\begin{array}{c}\text { waste water } \\
\left(\mathrm{ng} \mathrm{mL} \mathrm{mL}^{-1}\right)\end{array}$} & 0 & $10.2 \pm 0.3$ & $102 \%$ \\
\cline { 2 - 4 } & 10 & $20.8 \pm 0.6$ & $104 \%$ \\
\cline { 2 - 4 } & 20 & $29.0 \pm 0.3$ & - \\
\hline
\end{tabular}

\section{ACKNOWLEDGEMENTS}

Financial supports from National Nature Science Foundation of China (Grant No.21205028), Natural Science Foundation of Henan Province, China (Grant No.112300410080), Foundation for University Key Teacher by Henan Educational Committee (Grant No.2012GGJS-300) and the Seed Fund for Science and Technology creative talents of Henan University of technology (Grant No.11CXRC11) are gratefully acknowledged.

\section{REFERENCES}

1. Chinese Environment Protection Agency. Analysis Method of Water and Waste Water, Environmental Science Press, Beijing, China, (1989).

2. Gomez M.M.G, Garcia M.M.H, Corvillo M.A.P. Online preconcentration of silver on a sulfhydryl cotton microcolumn and determination by flowinjection atomic-absorption spectrometry, Analyst. (1995), 120: 19111915.

3. Environmental Protection Agency(EPA). Ambient Water Quality Criteria for Silver, Office of Water Regulation, Washington, (1980).

4. Wang Y, Chen M.L, Wang J.H. New developments in flow injection/ sequential injection on-line separation and preconcentration coupled with electrothermal atomic absorption spectrometry for trace metal analysis, Applied. Spectrosc. Rev. (2007), 42: 103-118.

5. Camel V.S. Solid phase extraction of trace elements, Spectrochim. Acta B. (2003), 58: 1177-1233.

6. Liang P, Peng L.L. Determination of silver(I) ion in water samples by graphite furnace atomic absorption spectrometry after preconcentration with dispersive liquid-liquid microextraction, Microchim. Acta. (2010), 168: 45-50.

7. Zhai Y.H, Liu Y.W, Chang X.J, Chen S.B and Huang X.P. Selective solidphase extraction of trace cadmium(II) with an ionic imprinted polymer prepared from a dual-ligand monomer, Anal. Chim. Acta. (2007), 593: 123-128.

8. Pons C, Forteza R, Cerda V. Multi-pumping flow system for the determination, solid-phase extraction and speciation analysis of iron, Anal. Chim. Acta. (2005), 550: 33-39.

9. Mahmoud M.E. Selective solid phase extraction of mercury(II) by silica gel-immobilized-dithiocarbamate derivatives, Anal. Chim. Acta. (1999), 398: 297-304.

10. Lee C.H, Suh M.Y, Choi K.S. Determination of Ru, Rh, Pd, Te, Mo and $\mathrm{Zr}$ in spent pressurized water reactor fuels by ion exchange and extraction chromatographic separations and inductively coupled plasma atomic emission spectrometric analysis, Anal. Chim. Acta. (2003), 475: 171-179.

11. Kagaya S, Saiki M, Malek Z.A. Coprecipitation with lanthanum phosphate as a technique for separation and preconcentration of iron(III) and lead, Fresenius J. Anal. Chem. (2001), 371: 391-393.

12. Sun Z.M, Liang P, Determination of $\mathrm{Cr}(\mathrm{III})$ and total chromium in water samples by cloud point extraction and flame atomic absorption spectrometry, Microchim. Acta. (2008), 162: 121-125.

13. Shemirani F, Yousefi S.R. Selective extraction and preconcentration of 
cerium(IV) in water samples by cloud point extraction and determination by inductively coupled plasma optical emission spectrometry, Microchim. Acta. (2007), 157: 223-227.

14. Turker A.R. Separation, preconcentration and speciation of metal ions by solid phase extraction, Sep. Purif. Rev. (2012), 41: 169-206.

15. Turker A.R. New sorbents for solid-phase extraction for metal enrichment, Clean: Soil, Air, Water. (2007), 35: 548-557.

16. Lemos V.A, Teixeira L.S.G, Bezerra M.D, Costa A.C.S, Castro J.T, Cardoso L.A.M, de Jesus D.S, Santos E.S, Baliza P.X and Santosi L.N. New materials for solid-phase extration of trace elements, Appl. Spectrosc. Rev. (2008), 43: 303-334.

17. Safavi A, Iranpoor N, Saghir N. Directly silica bonded analytical reagents: synthesis of 2-mercaptobenzothiazole-silica gel and its application as a new sorbent for preconcentration and determination of silver ion using solid-phase extraction method, Sep. Purif. Technol. (2004), 40: 303-308.

18. Savio M, Parodi B, Martinez L.D, Smichowski P and Gil R.A. On-line solid phase extraction of $\mathrm{Ni}$ and $\mathrm{Pb}$ using carbon nanotubes and modified carbon nanotubes coupled to ETAAS, Talanta. (2011), 85: 245-251.

19. Sarkar A.R, Datta P.K, Sarkar M. Sorption recovery of metal ions using silica gel modified with salicylaldoxime, Talanta. (1996), 43: 1857-1862.

20. Ellman G.L. Issue sulfhydryl groups, Arch. Biochem.Biophys. (1959), 82: 70-77.

21. Maquieira A, Elmahadi H.A.M, Puchades R. Immobilized cyanobacteria for online trace-metal enrichment by flow-injection atomic-absorption spectrometry, Anal. Chem. (1996) 66: 3632-3638. 